\title{
THE CONSTRUCTION COMMON PRODUCT CODING SYSTEM AND AUTO ID TECHNOLOGY IN CONSTRUCTION
}

\section{Nai-Hsin Pan}

Graduate School of Construction and Property Management, St. National Yunlin University of Science and Technology, Douliu, Taiwan, R.O.C., pannh@yuntech.edu.tw

\section{Recommended Citation}

Pan, Nai-Hsin (2009) "THE CONSTRUCTION COMMON PRODUCT CODING SYSTEM AND AUTO ID TECHNOLOGY IN CONSTRUCTION," Journal of Marine Science and Technology. Vol. 17: Iss. 4, Article 3.

DOI: $10.51400 / 2709-6998.1982$

Available at: https://jmstt.ntou.edu.tw/journal/vol17/iss4/3

This Research Article is brought to you for free and open access by Journal of Marine Science and Technology. It has been accepted for inclusion in Journal of Marine Science and Technology by an authorized editor of Journal of Marine Science and Technology. 


\section{THE CONSTRUCTION COMMON PRODUCT CODING SYSTEM AND AUTO ID TECHNOLOGY IN CONSTRUCTION}

Nai-Hsin Pan* have also started to implement Auto ID technologies for a limited number of applications. The focus of these applications has primarily been limited to the internal operations of a few larger companies. This means that the benefits of the new technology are confined within the operations of the company itself and information transfer from outside the company still tends to involve the manual recording and remanufacturing of information for use within the company. One of the major barriers to adoption of modern Auto ID in the construction industry is the lack of a uniform construction common product code system (CCPCS). Other industries, such as the grocery industry, have faced similar problems but have developed industry-wide solutions. As a result, virtually all products in the grocery industry originating from various suppliers can be identified by scanning the bar coding label at any supermarket in the country. The main objective of this research is to investigate the problems created by inadequate uniform information transfer standards and to create a suggested framework for information transfer. This could result in improving the communication of information between different components of the construction process by using new Auto ID technologies in the construction industry. A key component to achieve a solution is the development of a CCPCS for information transfer of external data and which will have sufficient robustness to accommodate a wide variety of existing Auto ID technologies and to accommodate newer systems which are appearing. An organizational framework which could be utilized in moving toward the development of a set of Auto ID standards for construction is suggested with a heavy emphasis in utilizing the extensive efforts already put forty in similar developments in other industries. Materials and components management is the primary focus of this study although the results would be applicable across the construction system of planning, design, construction and operation.

Auto ID has grown rapidly in various industries. Especia bar coding is one of the technologies which have already been implemented successfully in many industries. During the last couple of years, a small number of construction companies

Paper submitted 04/09/08; accepted 07/31/08. Author for correspondence: Nai-Hsin Pan (e-mail: pannh@yuntech.edu.tw).

*Graduate School of Construction and Property Management, St. National Yunlin University of Science and Technology, Douliu, Taiwan, R.O.C.

\section{Bar Code Technology}

Bar code is a widely used Automatic identification technology. A primary reason for this is because, the price, the speed and accuracy of bar coding is better than any other Automatic data identification technology at the present time. Bar codes are accurate in capturing data, and reduce mistakes which in data entry can be very costly. The familiar bars and 
spaces of the bar codes symbol are read by computers equipped with optical scanning devices. The scanners read the codes and enter data directly into a computer far more quickly and accurately than human key punch operators. Typically, key entry operators enter data at a rate of two to three characters per second. Bar code data entry rates are 30 characters per second and higher. The typical key operator makes one error in every 300 characters entered [11]. This error rate can be reduced to one in every three million characters entered when bar code data entry is used. The bar code symbols are actually a code corresponding to combinations of digits, letters or other punctuation symbols, which identify the item, its producer and any other information necessary to identify it or control its movement. The symbol is scanned and transmitted directly into a computer as data, identifying the product or component in several possible ways.

The scanners that read the various symbols contain a source of intense light, usually produced by a laser or light-emitting diode, aimed at the pattern of narrow and wide bars and spaces. The dark bars absorb the light; the spaces reflect it back onto the scanner. The scanner then transforms the patterns of light and dark into electrical impulses that are measured by a decoder and translated into a binary code for transmission to the computer.

In other industries, bar code application is particularly useful on rapidly moving conveyor belts, assembly lines, at supermarket checkout, and is widely utilized in general merchandise retailing, Automotive, health care and government applications. In other applications, accurate data entry allows paperless systems to be implemented.

\section{Radio Frequency Identification (RFID) Technology}

Radio frequency identification (RFID) refers to a branch of automatic identification technologies in which radio frequencies are used to capture and transmit data. Radio frequency identification technology involves the use of tags, or transponders that can collect data and manage it in a portable, changeable database within the tag; communicate routing instructions and other control requirements to equipment; and which can withstand harsh environments. RFID can be viewed as a sister technology to bar code labels which use radio waves instead of light waves to read a tag [6]. Tags can be categorized as read only or have both read and write capabilities. Moreover, they are classified as active, which means they include a battery, or passive, which means they are powered by the reader's energy field. The memory capacity of the tags varies from 64 to 32,768 bytes (one byte equals eight bits of binary code) [6]. Ghanem proposed a new model based on wireless communications technologies, to track the progress of percentage completed in a construction project based on Radio Frequency Identification (RFID) system [5]. Song presented an approach by which materials tagged with radio frequency identification (RFID) tags can be automatically identified and tracked on construction sites, without adding to regular site operations [11]. Ergen identify how RFID tech- nology can improve current facility management processes and to determine technological feasibility of using RFID within a facility repetitively on a daily basis [3]. Chin presents a strategy and information system to manage the logistics and progress control of structural steel works under the integrated environment of radio frequency identification and fourdimensional computer-aided design (4D CAD) considering the characteristics of the manufacturing and erection processes of structural steel works in high-rise building construction from a practical point of view [2].

\section{Value of a CCPCS}

When a company considers implementing new Auto ID technologies for any reason, the company generally decides whether the application fields are limited to internal use or extended to external use. If the system is just for internal use, the company will set up their own system and probably develop the internal standards for the company itself. However, there are more difficult information-communication problems if it is intended to interface with an external system. An industry standard only plays a recommended role for internal use while it plays a necessary role for external use.

During past the several years, as some new Auto ID technologies have been coming into wider use, it is becoming impossible to limit the capabilities of Auto ID system to internal applications only [12]. Many companies in the Automobile industry, the grocery industry or the electronic industry have already extended the capabilities of Auto ID to external systems. External systems are used to communicate between companies or other entities, rather than just internally.

Prior to computer systems, there was less formality in how products were identified. Typically, verbal and written communications, including purchase orders, used product descriptions. When descriptions became too long and cumbersome, "catalog" or "art" numbers were assigned [9].

As computer systems came into common use, individual manufacturers, distributors, and end customers often set up their internal computer systems using unique methods of identification. The manufacturers, distributors, and end customer would set up "stock" numbers. Thus, each company in the distribution channel could be using different numbers or format variation for the same product. The result is a tower of Babel with translation often done by order entry and/or receiving clerks from product descriptions or foreign numbers on purchase orders and product packages [9]. After translating the description or the foreign number" of the product to the company internal number, the translation is often recorded on another piece of paper and key entered into a computer system.

Now that electronic data interchange (EDI) is becoming prevalent, business is increasingly aware of the cost and complexity created by the multiple numbering systems. The principle of EDI is that trading partners' computers talk to each other via telephone lines, transmitting routine transactions like purchase orders, acknowledgments, and invoices 
without human intervention. For such communications, computers require exact product identifications in order to understand each other.

The impact of bar code applications has also been recognized by many industrial sectors. The most familiar example is the UPC system, universally used in the grocery products industry and becoming widely used in other retail areas.

Whereas the focus in internal systems is building in the flexibility to work with existing systems for material control, labor accounting, and others, the UPC experience shows us that the game in external systems is the development of industry standards.

It is easy to see why this is so. Consider the example of the customer who has decided to extend his internal data collection system to incorporate data from his suppliers so that he can quickly get control of materials once he receives them. He will want certain key information like product identification described on a label or other identifying medium attached to the product in a format which can be accurately, conveniently and uniformly read on the jobsite. This information could be in bar coded or other forms. The format of the label may be somewhat arbitrarily decided.

Consider the situation of the supplier who has dozens, hundreds or thousands of customers who wish to have coded information supplied with the product. If only a small percentage of them demanded this service and they all wanted different product identification formats this would be a major problem for the supplier and could soon result in a totally unworkable situation.

These kinds of problems are leading supplier and users in major industry groups to band together to standardize product numbers. Some of the active industry groups include AIAG (Automotive), LOGMARS (DOD), UCC (retail, grocery, electric).

The concept that all trading partners in a distribution channel should use the same identification for a unique product is now widely accepted by most industries. This standard identification be used in both paper and electronic communications is also widely accepted. Such standard identification allows for dramatic improvement in efficiency and accuracy in manufacturer, distributor, and end customer operations. This standard identification could be categorized into two types of numbering system based on the characteristics. One is branded product identification number, Uniform Product Code (UPC) is the typical example maintained by Uniform Code Council in industries. The other is the concept of CCPCS; Standardized Product Identification Numbers (SPIN) is the typical example which is maintained by Industry Bar Code Alliance (IBCA). Those two types of numbering concept will be discussed later.

\section{Branded Product Identification Number (BPIN)}

The advantage of a BPIN number is that it is easily assigned and maintained. Also, it could identify who manufactured the product. However, the disadvantage for the construction industry is that the identification number for the same or equiva-

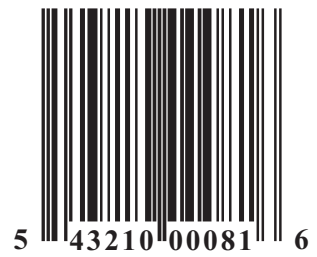

Fig. 1. UPC Sample.

lent item from different manufacturers will be different. It is inefficient to handle the equivalent or same construction items using different identification numbers for a construction company, especially during the construction operation.

\section{Uniform Product Code (UPC)}

The Uniform Product Code (UPC) standard numbering system is an internationally accepted method of identifying products, serializing shipping containers and clearly communicating other important business transaction data such as purchase order numbers, expiration dates, lot numbers, etc., in a standard, machine readable (bar code) and human readable format. The UPC number concept evolved in both industrial and retail channels which is a typical BPIN. A UPC number is used to identify a single product, and is twelve digits in length. These twelve digits consist of six digit manufacturer identification number, followed by a five digit item number, followed by a one digit calculated check digit [1]. The manufacturer identification number is obtained by each manufacturer from the Uniform Code Council (UCC) in Dayton, Ohio. Item numbers are assigned by each manufacturer to each unique product. These must be all-numeric (no alpha characters, punctuation or spaces) and 5 digits in length. Some manufacturers choose to arbitrarily assign these numbers, starting at "00001" and incrementing by 1 for each item. The calculated check digit is the twelfth and final digit in the UPC code as shown in Fig. 1. It is calculated based on a specific algorithm, and is necessary to ensure that the number is read or key-entered correctly. The objective of the UPC standard is to improve communication between trading partners by establishing a precise but flexible method of uniquely identifying products and package quantity in both human readable and machine readable formats. In some industries, the use of the Uniform Product Code (UPC) facilitates commerce on a worldwide basis [10]. In addition to defining a standard method of assigning part numbers, carton serial numbers and identifying secondary information, the UPC Standard Numbering System also specifies which symbology to use for each different number. The Table 1 below describes which numbers to use on different types of items and what symbology to use.

\section{Standardized Product Identification Numbers (SPIN)}

The Industry Bar Code Alliance(IBCA) developed a standardized method for identifying commodity type products known as SPIN for items that do not fall under the category of 
Table 1. Comparison of UPC and SPIN.

\begin{tabular}{|c|c|c|c|c|}
\hline MFR & UPC & SPIN & CAT \# & DESCRIPTION \\
\hline A & 74213512345 & 66817305070 & 14 C049T & $\begin{array}{c}1 / 4 \times 1 / 8 \text { STD BLK MAL } \\
90 \text { REDUC ELL }\end{array}$ \\
\hline B & 12345605070 & 66817305070 & $6923 Z$ ZF633 & $\begin{array}{c}1 / 4 \times 1 / 8 \text { STD BLK MAL } \\
90 \text { REDUC ELL }\end{array}$ \\
\hline B & 12345612345 & 66832112345 & 6924 XX923 & $\begin{array}{c}3 / 8 \text { WROT COPPER } \\
\text { ADAPTER FTG X F }\end{array}$ \\
\hline C & 98765424534 & 66832112345 & TX123 & $\begin{array}{c}3 / 8 \text { WROT COPPER } \\
\text { ADAPTER FTG X F }\end{array}$ \\
\hline
\end{tabular}

Table 2. The basic structure of UPC standard numbering system.

\begin{tabular}{|c|c|c|c|}
\hline Item Being Identified & Number Format & Information in the Bar Code & Symbology \\
\hline Consumer Unit & digit PC" & Product Identification & UPC version A or E \\
\hline $\begin{array}{c}\text { Intermediate Carton or } \\
\text { Pallet }\end{array}$ & $\begin{array}{c}\text { Product Identification } \\
\text { Symbol (SCS) }\end{array}$ & $\begin{array}{c}\text { Interleaved 2 of 5 or UCC/EAN 128 } \\
\text { w/ an Application Identifier } \\
\text { "01” }\end{array}$ \\
\hline Shipping Container & $\begin{array}{c}\text { digit Serial Shipping Container Code } \\
\text { (SSCC) }\end{array}$ & $\begin{array}{c}\text { Serial number uniquely identifying a } \\
\text { shipping container, pallet, etc. }\end{array}$ & $\begin{array}{c}\text { UCC/EAN 128 with an Application } \\
\text { Identifier of “00” }\end{array}$ \\
\hline Anything & $\begin{array}{c}\text { Length varies but the symbol includes } \\
\text { Application Identifiers to designate the } \\
\text { type of information in the bar code }\end{array}$ & $\begin{array}{c}\text { Secondary information such as } \\
\text { purchase order number, lot number, } \\
\text { etc. }\end{array}$ & UCC/EAN 128 \\
\hline
\end{tabular}

general trade items which are manufacturer-specific" like those assigned in UPC. IBCA developed this method to assist those market segments wishing to group products classified as commodities in a common inventory. A product commodity is defined as an item whose form, specification, and function do not vary from one manufacturer to another [12]. The method uses the eleven-digit all numeric structure of the UPC but replaces the manufacturer ID with a commodity group ID and also assigns the five-digit product ID. In combination, these eleven digits form the SPIN number. The UPC is a form of product identification that is unique for a specific manufacturer which could be defined as a Branded Product Identification Number (BPIN). Another form of product identification is for those items which are not unique to one manufacturer. Examples are brass fittings or copper piping. These have historically been called commodity items. Although some manufacturers have worried that they will lose their identity, the many manufacturers involved have found this not to be the case and that the benefits to distributors and users are enormous. The UCC has set aside a range of numbers that will not be assigned to manufacturers, thus avoiding any confusion.

The method for determining what products should be considered commodities and then developing a common terminology and finally assigning index numbers is a systematic procedure conducted by a committee made up of manufacturers and distributors of those types of items. Most of the work has been done, although occasionally new groups are identified by the companies involved. The advantage is that the SPIN is universally understood to represent a given item, regardless of manufacturer or vendor. However, the only commodity groups that IBCA was concerned with were plumbing and some HVAC items. IBCA was not trying to solve the world needs for all items; but there is a larger need that other groups have and they will have to address them, especially in the construction industry. Examples of typical SPIN number files are shown in Table 2. The UCC Identification Number for Manufacturer 'A' is 742135 ; for ' $\mathrm{B}$ ', it is 123456; and for ' $\mathrm{C}$ ', it is 987654 . Notice that although the UPC is different, the SPIN's are the same (668173-05070 and 668321-12345). The advantage/disadvantage analysis of BPIN and commodity code for the construction industry could be summarized in Table 3. Later, this research will examine the essential features which would be involved in the establishment of industry-wide information transfer standards in the construction industry with a particular focus on the problem of materials and components management.

Given the complexity and diversity of the construction process, any effort at overall standardization must be carefully worked out or the activity will be doomed to fail. Therefore, it is necessary to identify what information would be the most important target for an industry-wide standard. This research is aimed at studying the information flow associated with construction and subsequently selecting those items that would be most appropriate for standardization. 
Table 3. The advantage/disadvantage of BPIN and CCPCS.

\begin{tabular}{|c|c|c|}
\hline & Advantages & Disadvantages \\
\hline $\begin{array}{l}\text { Branded Product Identification Number } \\
\text { e.g. UPC }\end{array}$ & $\begin{array}{l}\text { - Easily assign and maintain. } \\
\text { - Manufacturer specific. }\end{array}$ & $\begin{array}{l}\text { An ID number different from different } \\
\text { manufacturers for the equivalent item. }\end{array}$ \\
\hline $\begin{array}{l}\text { CCPCS Number } \\
\text { e.g. SPIN }\end{array}$ & $\begin{array}{l}\text { - A uniform ID number which will not change } \\
\text { from one manufacturer to another. } \\
\text { - Material group indexing. }\end{array}$ & $\begin{array}{l}\text { - More difficult to assign. } \\
\text { - Convenient on job site but may be more } \\
\text { difficult for designers to specify items. }\end{array}$ \\
\hline
\end{tabular}

\section{BASIC STRUCTURE OF CCPCS}

CCPCS permit buyers to specify material components regardless of vendor. Common numbering schemes also facilitate the transfer of materials information between designer or owner and the construction contractor. However, to assign a unique material or components identification using the CCPCS concept is more difficult than the previous methods. A commodity code scheme results in the assignment of unique numbers to items. The number assignment process is complicated when a large number of factors can be varied to create many combinations of specification parameters. Also, it is more difficult for the architect or designer to refer to the new assigned unique material identification number instead of traditional material description.

However, the concept of a CCPCS could make a specified item or building product to be recognized uniformly by all parties involved in the construction operation (e.g. supplier, contractor, designer/architect) by using a unique number. Based on the description above, from the basic construction material identification standpoint, using the method of CCPCS will be more suitable than the method of BPIN at the present time.

Using the CCPCS concept could provide a uniform approach to develop a construction materials information classification system for basic construction items.

Any references to "codes", "coding structure", or "numbering system" are meant to be completely symbology-independent. This means we are only referring to numbers (and in some cases, letters too) that are used to identify or describe something and which are a convenient format for the computer.

No matter what types of different information will be required to be exchanged among parties, data transfer in the construction process could be categorized into two major groups:

\section{- Object Identification (Primary Information); - Application Identification (Secondary Information).}

The two information groups will be examined in detail in the following sections.

\section{OBJECT IDENTIFICATION}

Object identification provides industry-wide information which would generally be of a long-term nature. Included in this class could be organizational units such as client, design firm, manufacturing company, or other organizational unit involved in the construction process. Another type of information could be item identification. This identification would be related to the object and does not change when the object identification is used by different organizations. An example of object identification can be seen by examining the UPC basic coding.

This research will focus on the construction material/building component identification as a module because construction material cost occupies $50 \%$ of the total project cost. Also, from the viewpoint of Material Management, material is the primary information needed to be identified. The standardization for code structure of product identification is one of the most complex parts in industry-wide standardization. Construction material tracking and management can involve literally millions of different items from a vast array of manufacturers and suppliers. For example, distinctions can be made about the physical scale of objects whose data are stored and exchanged. Relevant classes include information about regional objects or systems, information at the (building) project level, information at the level of the individual unit or object, information at the level of complex components or object parts (doors, walls, bathrooms), and information at the level of individual components such as beams, pipes, bath tubs, and nails. When they are ordered, shipped, delivered to jobsite, it is necessary to make sure that these items conform to what was specified. To solve this problem, there is a need to establish uniform procedures for vendor product identification. Of particular concern is determining which products (if any) should be identified with a uniform commodity code. If a commodity code approach is used the product identification must use the same identifying number for generic class, regardless of manufacturer. Using the concept of CCPCS, an example of a suggested information structure for pipe is shown in the Table 4.

The concept of a CCPCS could make a specified item or building product recognized by all parties involved in construction operations (e.g. supplier, contractor, and designer/ architect). The construction industry does involve the metal industry or pipe industry but the building items in the construction process come from many different fields. The current concept of a CCPCS is for the identification of similar products (e.g. pipe made of carbon and pipe made of stainless steel). Therefore, construction industry standards should also be able to identify different items during the construction process (e.g. door, wall, pipe, form, glazing, equipment, etc.) 
Table 4. Recommended data fields for process pipe data tables.

\begin{tabular}{|c|l|}
\hline & \multicolumn{1}{c|}{ Definition } \\
\hline $\begin{array}{c}\text { Specification Standard } \\
\text { For Material (Metallurgy) }\end{array}$ & ASTM or API Standard (i.e., ASTM A106, API 5L or ASTM A53, etc.) \\
\hline Grade & Grade within the specification standard (i.e., ASTM A53 grade B or C or A106 grade A, B, or C, etc.) \\
\hline Processing History & $\begin{array}{l}\text { Pipe can be seamless or welded (EFW-electron fusion welded or SAW- submerged arc welded or } \\
\text { ERW-electro resistance welded) }\end{array}$ \\
\hline Size & The nominal outside diameter of the pipe (NPS) \\
\hline Wall Thickness or Schedule & The thickness of the pipe (OD-ID) \\
\hline Other & $\begin{array}{l}\text { The pipe could be coated and wrapped, cement lined, galvanized, ordered with beveled ends or } \\
\text { double random lengths. }\end{array}$ \\
\hline Metallurgy Description For Material & $\begin{array}{l}\text { Usually when specifying pipe, a broad description of the pipe metallurgy is given such as carbon } \\
\text { steel, stainless steel, 1 1/4 Chrome, 2 1/2 Chrome, low temp, carbon steel, etc. }\end{array}$ \\
\hline
\end{tabular}

\section{Package Level Identification}

The concept of the coding structure described above is used for the identification of a single item class. However, it would be very unusual that just a single product class or material would arrive on the job site as a single unit. Most of the items for the construction job arrive on the construction site as packages, shipping containers or bulk deliveries. Some of these packages or containers may contain a mix of different kinds of items. Sometimes, it is not suitable or efficient (e.g. time-consuming) to open every package or containers to check what the contents are. Thus, after defining the single item unit and assigning a product number according some established guidelines, it is necessary to also consider the packaging configuration. A packaging configuration is one unique hierarchical method of packing a product. Other industries (e.g. Retail industry and automotive industry) have faced the same problems. Manufacturers, distributors, and end customers typically deal with multiple levels of packaging of the same items. For example, a distributor may buy a full shipping container or even a full pallet of an item. He may break the container to sell intermediate containers or individuals consumer units to an end customer. When the transaction is recorded, either by key entry or using a bar code scanner, it is critical that the correct number of customer units be identified. Therefore, to identify higher levels of packaging (above the consumer unit) within a product packaging hierarchy, the packaging indicator concept was created. The Package Identifier will be 1 digit or 2 digits which are used to identify various levels of packaging and for defining the quantity contained within the package such as:

- Unit Pack: A pack contains standard or non-standard quantity of like items.

- Mixed Item Pack: A pack contains items with different product numbers.

- Multiple Pack: A pack containing smaller packages (sub packs) of items.

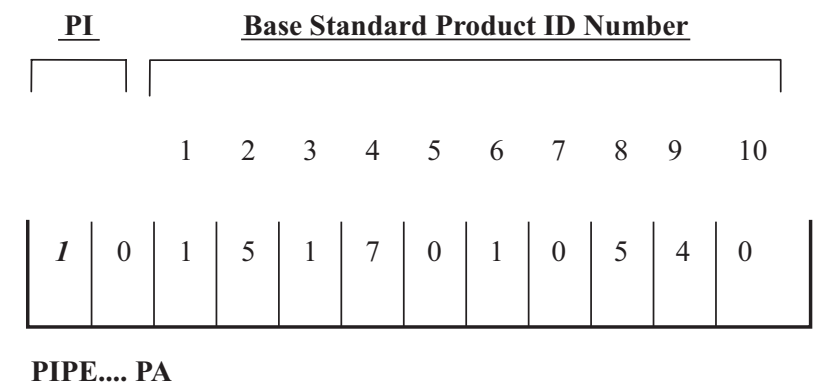

Fig. 2. Common commodity code sample.

For example:

In this example, the leading PI of 1 is used to identify the next level of packaging, above the item unit. Standardized PI with specific meanings has been adopted by some industries and companies. The construction industry could benefit by following similar recommendations and develop a standard suitable to the construction industry. The recommendations from UCC (1992) [1]. Publications could be referred to as one of the resources.

\section{APPLICATION IDENTIFICATION}

Using the construction operation on the jobsite as a starting point, in addition to the objects or items needed to be identified, there are other information which are related to the activities(e.g. accounting, purchasing, shipping, delivery, etc.) and parties involved(e.g. addresses, phone number). Thus in addition to the product identification there is also information about products like shipping date, manufacturers name, weight, quantity shipped, etc., and a construction industry standard for automated information transfer must also provide a capacity to include this secondary information somewhere in the process. For example, when the materials/products are ordered by the field office, they are then shipped to the job. The field office not only must identify the products themselves and whether they are in fact the products ordered but also need to know the 
quantities of particular shipments and the linkage to job management and accounting operations. The field and central offices will retrieve files of related purchase orders to check information of material and component receipts against items and quantities required and ordered. As a result there are at least two other packets of secondary information the field office needs to know. First, the information attached with the product/material must either supply the purchase order number or a link to this information which may be in a computerized database for larger contractors or filed information for smaller contractors. It could help the field office to efficiently retrieve the files of purchase orders which may be particularly extensive in a complex project. Second, it also should include the information regarding the quantity of the item included in the particular shipment. This also would help the field office check the shipped product quantity against orders to determine whether this matches the information in the purchase order. This would be an especially important process in which automated data-processing technologies could make an important contribution. The example described above represents one of the possible applications.

\section{Dates}

Some products need to be identified with specific critical dates, such as production date, packaging date, warranty date, shipping date. In bar code application, the decision regarding whether to bar code dates depends on the importance of the information or the frequency with which such data may need to be collected by the manufacturers, supplier, or user.

Some examples of the use of bar code labeled dates include:

1. The manufacturer, supplier, or user may wish to scan shipments to ensure that old and expired materials are not shipped for use.

2. The manufacturer, supplier, or user may wish to scan inventory to discard old material, or their computer systems may be programmed to create warnings of inventory nearing obsolescence.

Computer systems may be programmed to automatically find the oldest material in stock and identify its location as order picking documents are printed, to ensure first-in/first-out.

\section{Serial Number}

Commodity ID number is defined as "primary" product identification and serial numbers are defined as one form of "secondary" product identification. Serial numbers are identification codes assigned to specific product units. Typically, serial numbering is used for relatively expensive products versus less expensive or highly dispersed products. Examples may be an air handler unit or air conditioner vs. a load of two by fours. More and more manufacturers, in many industries, are bar code labeling serial numbers to gain the advantages of more efficient data entry and more complete and accurate information. Such benefits need not be limited to manufac- turers. In construction, serial numbers could be attached to some expensive equipment, or prefabricated building components. This would aid the construction company in tracking inventory. Inspectors can keep track of warranty date, and quality. End users can keep records of service, or performance. This number could be for external use.

\section{EXAMPLE OF THE APPLICATION OF CCPCS FOR AUTO ID IN THE CONSTRUCTION PROCESS}

The potential of Auto ID technologies are becoming recognized in the construction industry and some firms in the construction industry have been willing to use Auto ID technologies for specific applications. The wider application of Auto ID technologies could be considered within a company itself for company-company applications for cross industry applications, and even for country-country applications. The success of such efforts would be dependent upon developing and implementing a CCPCS. However, any effort at overall standardization is very difficult because of the fragmented and institutional character of the industry and would probably be doomed to failure if an attempt was made to attack all aspects of the problems at one time. Therefore, selecting a target application as a pioneer and demonstration project might be a more practical way to proceed. As materials and component management involves a substantial portion of construction management costs and may show substantial improvements in efficiency and cost reduction this would be a very good target application to illustrate the problems and benefits in moving toward standardization of information.

A cost and benefit study [7] showed that significant gains have been made in materials management through the use of automated data collection and tracking and processing of data using computers. As more industries recognize the benefits which might be achieved, automated materials management will assume greater importance. There will be greater opportunities for improvement in productivity and quality, and less emphasis on manual labor for reading, recording and transcribing of data. The materials management activities performed at a construction jobsite are the final stage of a process that can have a significant effect on the cost and schedule of a project. Of all the factors that influence craft productivity and construction schedules, materials is one of the most controllable. Complex problems such as design errors and changes, burdensome codes and regulations, inefficient construction methods, and rigid craft jurisdiction/work restrictions all have a negative impact on productivity, but are difficult problems to solve. The delays caused by insufficient amounts of materials, however, can be controlled effectively by proper materials management. At a job-site field office, obtaining materials of the right type, quantity and quality in time to keep field construction moving in a timely manner might seem straightforward, but on a project of any size the process is complex indeed. More importantly, effective ma- 


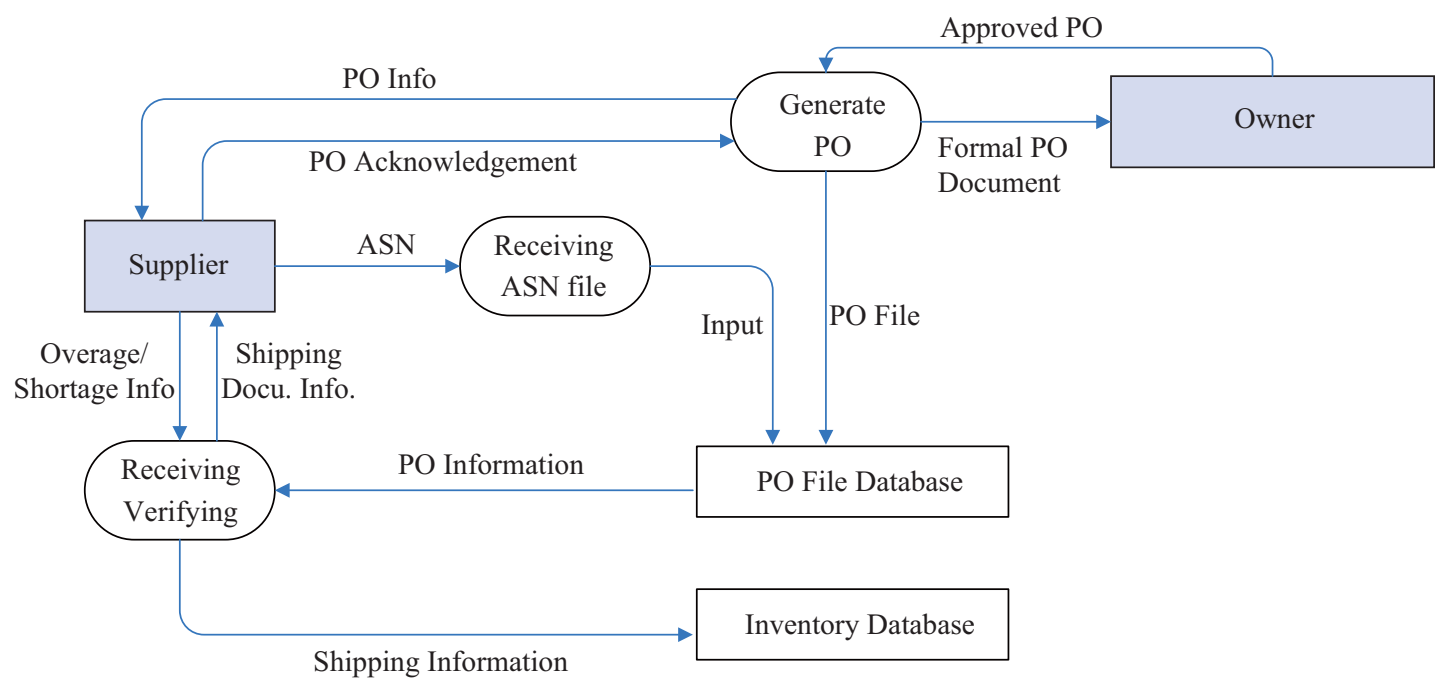

Fig. 3. General Contractor's Material management system (MMS) data flow diagram.

terials management is essential to the technical and financial success of any project. A materials management system for an industrial construction project includes the major functions of identifying, acquiring, distributing, and disposing of all bulk and engineered materials [12]. Automating a materials management system by using Auto ID technology, ex. bar code technology, can potentially reduce project costs by improving labor productivity, reduce materials surplus, and increase reliability of information. Bar code technology for materials management has made a major contribution to manufacturing and retail areas over the last 15 years. The same contribution is possible in construction despite the unique character of each construction project.

Thus, a materials procurement situation will be used to discuss the role of CCPCS in site-level materials management applications. In a materials procurement situation, for example, when a contractor decided to order steel pipes for a construction project use, the contractor places a purchase order (PO) to the supplier. After the PO is generated by the contractor's computerized material management information system (MMS), traditionally, the PO will be sent by mail or by fax. If MMS can link to the supplier's by EDI network, the PO could be transferred directly to the supplier's computer. The data flow diagram of MMS is illustrated in Fig. 3.

The suppliers receive their customer purchase orders the same day they were created, and transfer a PO Acknowledgment in return through internet notifying the customer that the PO have been received. Then, the suppliers process the PO automatically within their computer systems, and release picking orders to the warehouse. The supplier will attach a bar code on the requested product using the CCPCS as the purchase order requested.

Project expediters are charged with assisting material vendors in meeting their schedule commitments. To perform this function the expediter relies on the system to obtain in some

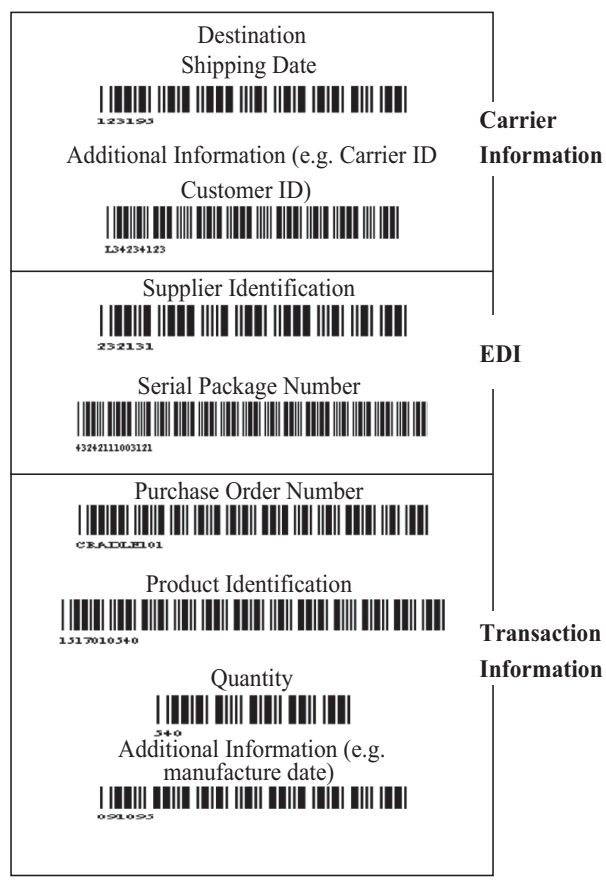

Fig. 4. A suggested shipping/identific ation label.

priority order current craft material requirements. After contacting the vendor, the expediter can alter the projected delivery dates in the system and/or add his own comments to a field in the purchase order file. On an interactive, or EDI system, this information becomes immediately available for use by other home office and field personnel.

When the field personnel receive the shipment, they will scan the bar code to verify the quantity and the quality of requested product. A suggested shipping bar code label in this project is shown in Fig. 4. This label is broken into three sections dedicate to specific information fields. 
(1)

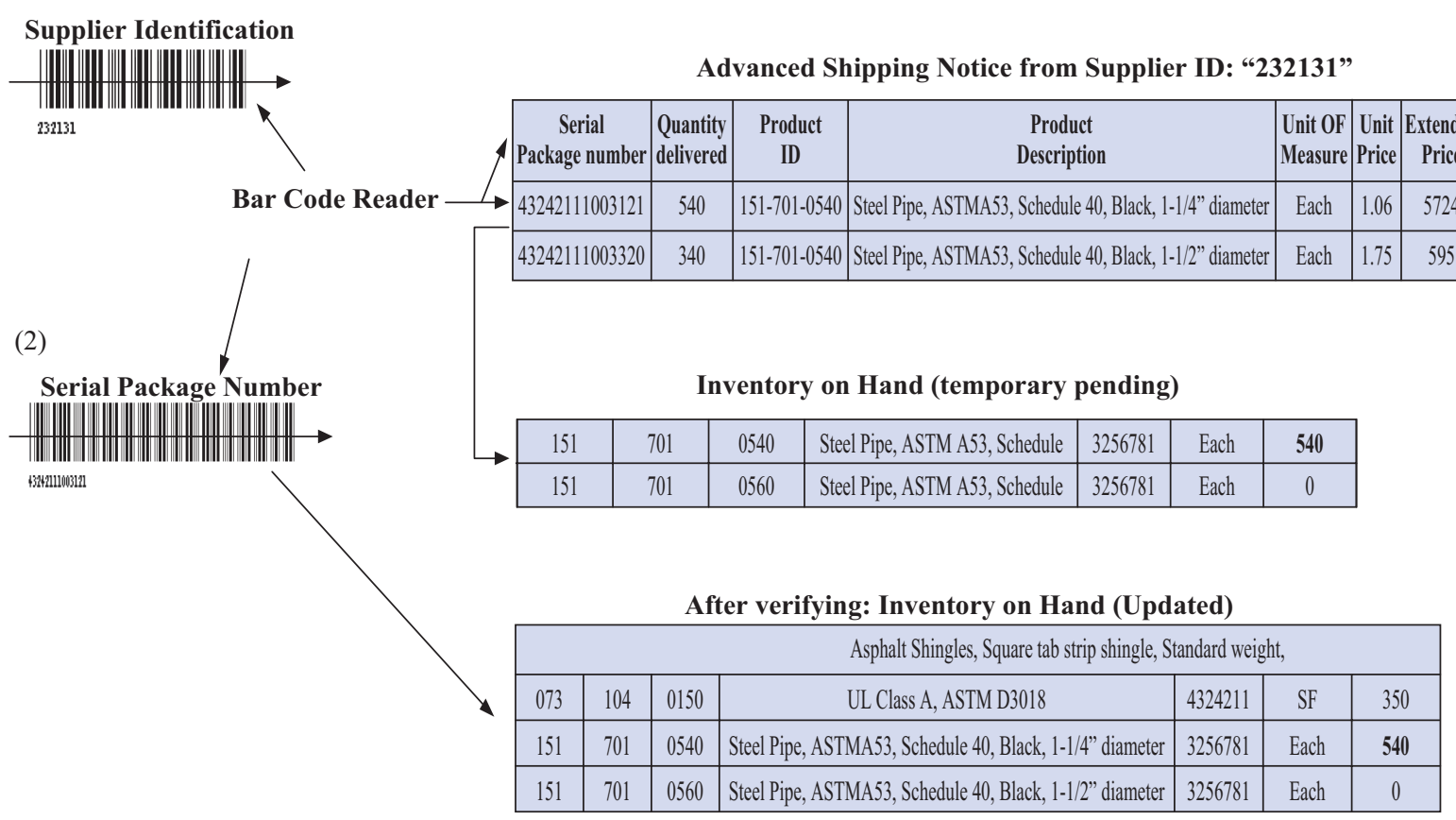

Fig. 5. Procedure 1: Verifying shipping process in internet and bar-code based system.

The carrier data field has room for:

- The Shipment's Postal Code Destination,

- Shipping Date,

- A Third Line for Additional Carrier-Related Data (e.g. Over-The-Road Carrier Identification).

In the shipping label of this project, The Shipment's Postal Code Destination"1422811234" indicates the location of the postal code for the use of carrier. This information will help the supplier or shipping company track this shipping. The Shipping Date "123195" indicate the shipping date "Dec, 31, 1995". Over-The-Road Carrier Identification "L34234123" identify the carrier (driver or truck) for the use of the shipping company.

A middle section covers customer (receiver) - related information. Two fields are dedicated to:

\section{- Supplier ID number, and \\ - Serial Package Identification Numbers.}

Assume the MMS links to the supplier through EDI system. The supplier identifies the specific shipment (e.g. single, mixed, pallet, or container) with the Supplier ID Number and the Serial Package ID Number, and transmits detailed information about the contents (including standard product numbers and quantities of each, specification, etc.), which is called Advanced Shipping Notice(ASN), to the receiving company through the network. The receiving company stores the transmitted information in their MMS. The MMS matches the this
Supplier ID Number and Serial Package Number scanned from the shipment to its database and displays the detailed contents of the shipment, as transmitted by the supplier. The procedure using the project as an example will be described as follows and shown in Fig. 5.

When the shipment arrives on the job site the receiver first scans the Supplier ID number of the bar code label, Supplier ID number "232131", the computer will withdraw the ASN file identified by the specific supplier ID number "232131". In this project, Supplier ID number " 232131 " is the unique standard code number which indicates the specific material supplier "DEF Pipe Co." which is shipping this requested material.

Second of all, the receiver scans the Serial Package Identification Number of the bar code label, Serial Package Identification "43242111003121"; the computer will look up the specific line item identified by this specific Serial Package Identification Number in the specific ASN file. Serial Package Identification " 43242111003121 " is the reference number the supplier assigned following the standard data format which indicates the particular shipping content in the case of trading partners that exchange information by using electronic data interchange. This could be known as the EDI license plate. The use of Serial Package Identification Number will be described more detail later. At the same time, the Inventory On Hand file will be automatically updated with new quantity on hand for these specific line items. However, at this time, without verifying and inspecting, the specific line items in the inventory file shows "pending". The receiving clerk should verify the contents and confirm accuracy, or make any neces- 
(1)

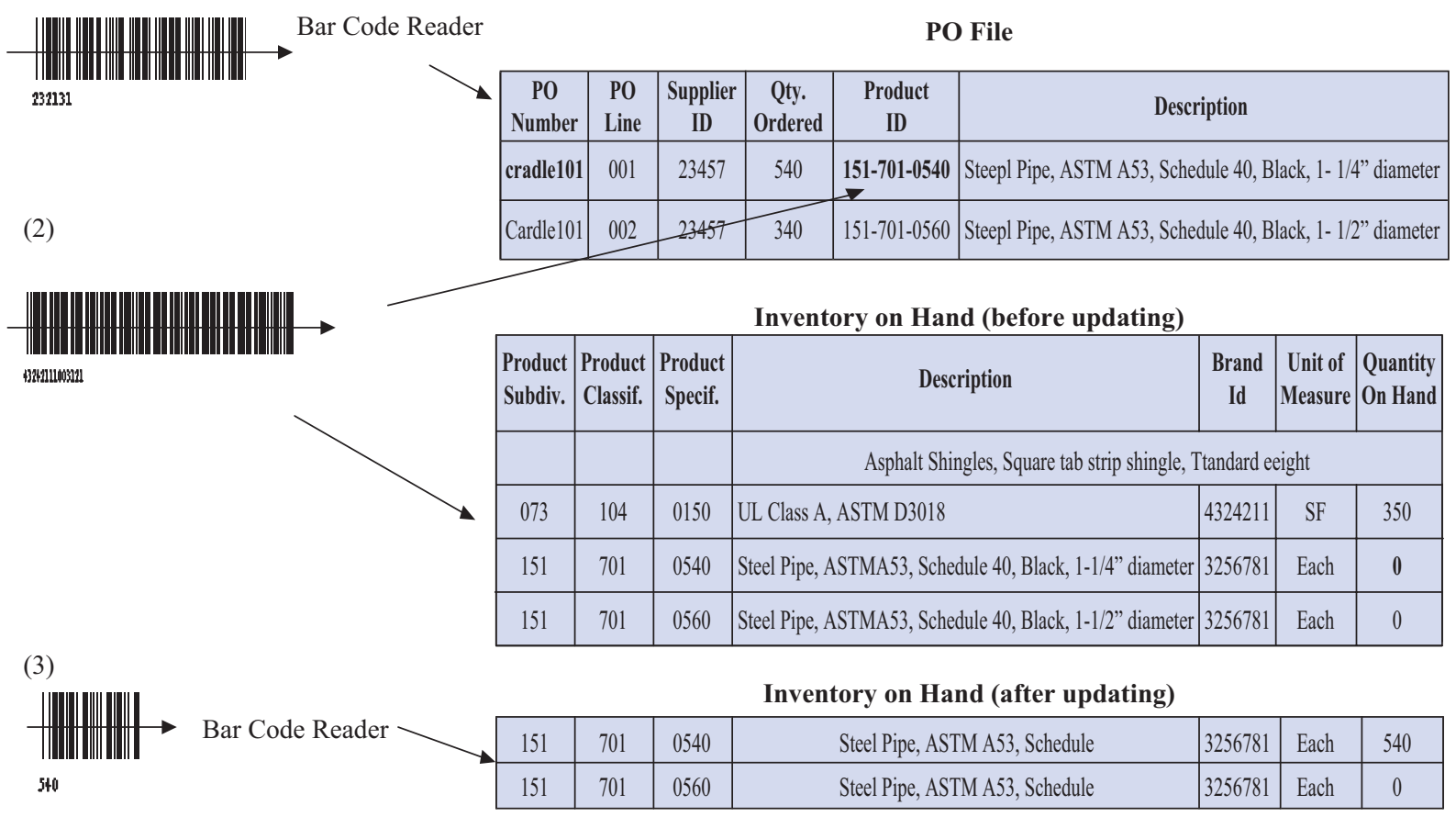

Fig. 6. Procedure 2: Verifying shipping process in bar-code based system.

sary corrections. Then, the computer automatically updates the formal inventory records for all the items in this shipment.

The final section of the label carries transactional data in case the receiver didn't EDI system. This field would include:

\section{Purchase Order Number,}

- A Unique Number (Industry-Wide Material Commodity Code) identifies the Material Item,

- A Material Description,

- Quantity, and

- Additional Transactional Data (e.g. Manufacture Process, Date).

Assume the MMS doesn't link to the supplier through internet. The supplier attaches to the specific shipment (e.g. single, mixed, pallet, or container) a bar-code label with the Purchase Order Number and Product Identification as the buyer requested. When the shipment is delivered to the receiver, the receiver scans these two labels to withdraw the requested line item from the database, and then verifies and inspects the specific shipment. If the shipment matches the items the purchase order requested, the shipment information will be updated into the inventory database. The procedure using the project as an example will be described as follows and shown on Fig. 6.

When the requested material is delivered to the receiving site: The receiver scans the bar-coding Purchase Order Number which the field office asked the supplier to attach in the shipping label of the project, Purchase Order Number "CRADLE
101". The computer will withdraw the original purchase order document identified by number "CRADLE 101" from PO file as shown in Fig. 5. Second of all, the receiver scans the bar-coding Product Identification in the shipping label of this project, the Product Identification " 1517010540 "; the computer will look up the line item with this specific product identification number. The Product Identification "1517010540" using CCPCS indicate the specific requested material "Steel Pipe, ASTM A53, Schedule 40, thread, Black, 1-1/4" diameter". After withdrawing the original PO file and verifying the quantity and quality of the shipment, the receiver could scan the Quantity field of the shipping label for this project, the Quantity "540" as PO requested, to automatically update the inventory database. Then the shipment contents can be matched to the original purchase order to automate the receiving the process, updating the inventory database and purchase order file.

There are at least two major advantages to the adoption of this suggested label standard or one similar to it. Initially the new standard would minimize the number of label formats any user would have to adhere to. In addition, the nature of the information in the label standard allows the vendor or jobsite to apply information pertinent to internal use. It must be recognized that multiple purchase orders might be combined on one shipment, or that the shipment represents only a part of the original purchase order. Any of the above approaches permit the ability to update purchase order records and job inventory records immediately upon the receipt of materials, the ideal for speed and efficiency. 
To develop the bar-coded based MMS just described, there is a major finding regarding bar-coded technology that needs to be addressed. If a construction company wants to track material from several different suppliers through bar-coded system, it may be difficult to get the suppliers to agree on the use CCPCS for a given required material. The other industries such as grocery industry, automotive industry which faced similar problems have already developed an industry-wide standard (i.e. UPC) for external system use, like supplier-to -supplier, user-to-supplier.

\section{THE BENEFITS OF CCPCS IN CONSTRUCTION}

The section describes what the impact (benefits) of industry standard will bring in the construction process, especially in material management.

The potential of CCPCS especially uniform product coding within the construction industry are very similar to other industries (e.g. retail/grocery industry/automotive). Traditionally, without CCPCS, there was less formality in how items coming to the jobsite were identified. Typical verbal and written communications, including purchase orders, and translation of specification document from designer or architect used product descriptions. Descriptions often became long and cumbersome and could be subjected to different interpretations.

As computer systems came into common use in materials management, individual manufacturers from a broad spectrum of industries (e.g. steel industry, pipe industries), designers, and construction firms started to develop identification schemes which would relate to computerized data bases. Unfortunately many of the parties in the construction process would set up different "item" or "product" number identifiers. Thus, different parties in the construction process could be using different numbers or format variations for the same construction product. The concept of CCPCS will make the different parties in the construction process use the same identification number for the same object. In the past, miss-communication between the different parties involved often led to misunderstanding and disputes have occurred. The adoption of CCPCS will facilitate the information transferring between a construction operating firm and its trading partners.

The interchange of information such as can be done through an EDI in which trading partners' computers "talk" to each other via telephone lines, transmitting routine transactions like purchase orders, and invoices without human intervention must have a common language. For such communications, computers require exact product identification and other basic information in order to understand each other. Newer opportunities to electronically interchange information, such as the use of the Internet impose the same requirements. These newer modes of communication offer an opportunity of more economical and widespread electronic interchange of information but also raise security issues which will require extensive investigation which has been summarized in earlier section.
A bar code system for materials management on an industrial construction project would entail an exchange of information about a product between the manufacturer, supplier, contractor, and owner within rigid rules defined in the industry standard. For example, a bar coded label attached to the product would display enough information so that each participant's computer database can retrieve information on the item but would be optimized to keep the on-product symbology as simple as possible. This information would include the item's origin, product type, purchase order number, quantity, and any other important features. This information would be used to design bar code applications that not only collect data, but direct, track, and validate an activity. Without the CCPCS, the capabilities of bar code technology, EDI, other data processing technologies are limited. Surveys conducted by Texas A\&M University show a considerable interest in the use of bar codes in the industrial construction industry. Some of firms responding to the surveys have developed internal standards for various bar code applications. The results of the surveys show that the lack of industry standards is the largest obstacle to inter-company use of bar codes within the industry. Without the CCPCS, for example, the bar code label attached when shipping a product probably could not be recognized by the receiver. The information decoded by the receiver's scanner has no meaning to the receivers, if both parties use different item coding. The result is a "tower of Babel," with translation often done by order entry and/or receiving clerks from product descriptions on purchase orders and product packages. After translating the description of the product to the company's internal number, the translation is often recorded on another piece of paper and key entered into a computer system.

The CCPCS will enhance adopting Auto ID technologies applications in the construction industry and extend the Auto ID technologies internal application to external application. The benefits of adopting Industry Standard are difficult to quantify. However, based on the other industry's experience and the example project above, the possible opportunities in construction process could be identified in the following as shown in Fig. 7.

\section{Information Transfer}

The engineer could use the standard code number to setup a product specification catalog instead of using written descriptions. To save time and cost, it is unnecessary to remanufacture this information especially using a computer system. It will reduce the errors related to human factors which include the misunderstanding during translation of specifications requirement.

\section{Receiving}

Each product received typically requires manual recording or verifying and manual lookup of the appropriate warehouse storage location, with all transactions typically key entered into a computer. Saving cost or time per transaction with bar code scanning in receiving is great. Also, consider reduction 


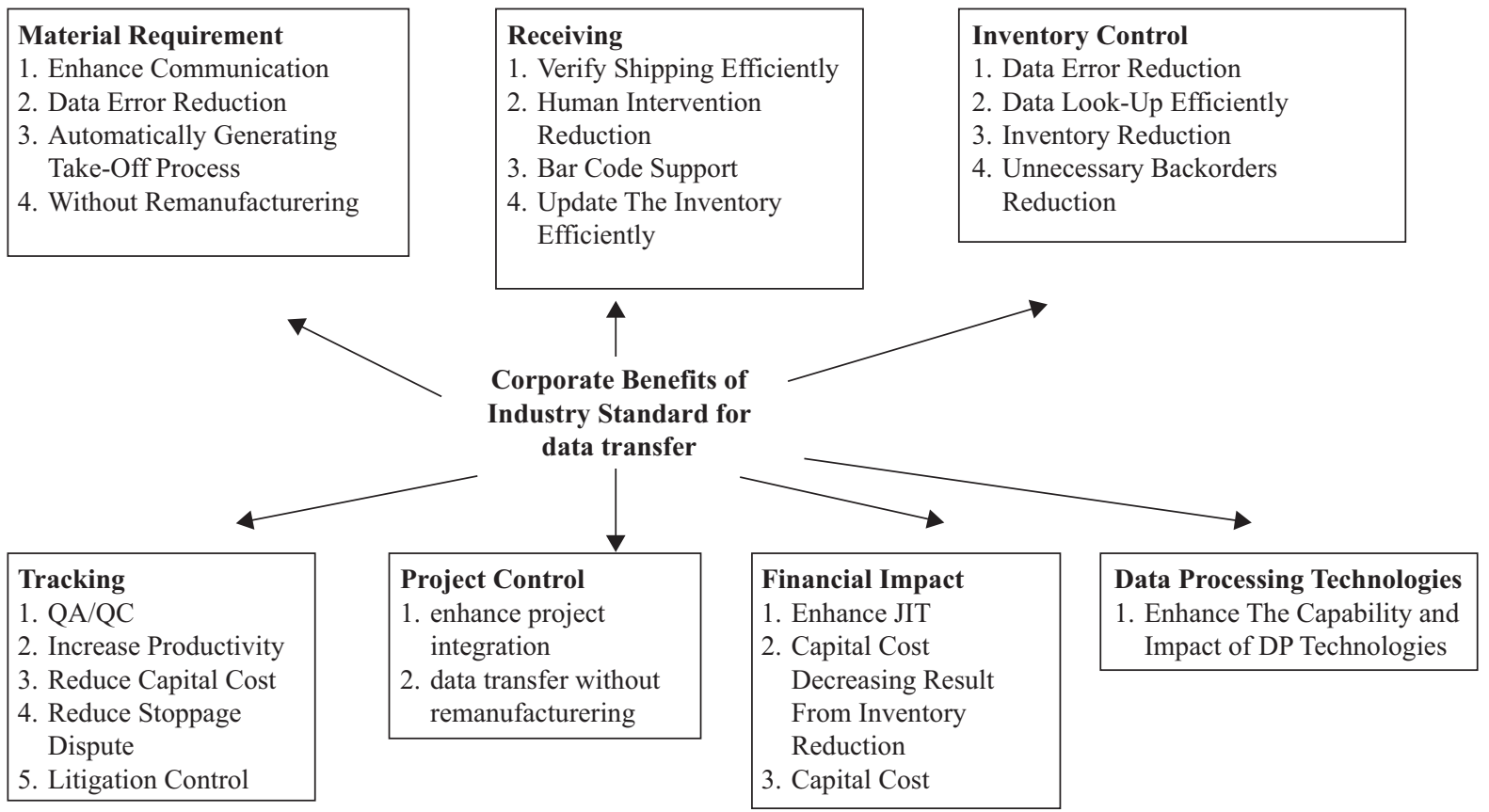

Fig. 7. The corporate benefits of adopting an industry standard in construction process.

in lead time to get the material into the inventory, and the resulting reduction of inventories. At each stage there are more transactions, multiplying the benefits of standard numbers and bar codes.

\section{Inventory Control}

Consider backorders, which occur when actual inventory does not exist as shown in computer records. These can be caused by errors in receiving, or by misplaced inventory, which the order filler can't find because of the different number format. Error reduction from CCPCS will typically result in significant reduction in backorders because of incorrect inventory record, and eliminating time spent fixing these mess situations. Also, consider the impact on contractors and supplier in construction operation of more reliable lead times and more complete shipments. Unreliable inventory records, caused by identification errors, are one of the major causes of excess inventories. Such errors also have an adverse effect on productivity.

\section{Tracking}

When the materials are received by the field personnel in the jobsite, the operator will depend on their specific needs to withdraw the materials they needed from the inventory to install. Therefore, the inventory records needed to be updated immediately to alert the surplus or shortage of the product so that they could decide whether it is necessary to backorder or not. Use of CCPCS to track the specific materials makes the inventory records more accurately and efficiently than written description. Less downtime and enhance the productivity of the labor are the results. To the contractors, it could reduce capital cost unnecessary purchase order. Also, for the use of $\mathrm{QA} / \mathrm{QC}$, it is necessary to track the where the materials or component have been installed and who were responsible for them. Also, the inspection data with standard format could be attached on the building component and materials. Once there is a dispute, that information could be a kind of legal proof. Use of CCPCS and bar code system could track the materials efficiently and accurately.

\section{Project Control}

Use of the CCPCS could make the information transfer through preliminary design, full design, estimating, scheduling, accounting, financial management, construction operation, and later in facility maintenance, historical record generation and of the renovation of the completed project without re-manufacturering the information in each procedure. Ideally, CCPCS could eliminate the need for re-keying information, reduce information errors, and result in the smooth transition of data from one computer program or computer system to another through the life cycle of project. It could make the different steps in the project control more tightly integrated.

\section{Financial Impact}

The implementation of CCPCS in construction process could result in avoiding a great amount of money tied up in the excess inventory because of the unreliable inventory records. Also, more efficiently tracking inventory information could reduce the capital cost on the unnecessary purchase order, and missing or stolen materials on the construction job sites. It is a fundamental part of that significant change in material-control 
philosophy called Just-In-Time (JIT). JIT is highly visible part of real-time management. The concept of JIT is that materials arrive at the point where they are needed exactly when they are needed--- neither too early nor too late.

\section{Auto Identification Technologies (Auto ID) and EDI}

Some industries traditionally use customer assigned part number. For example, automobile manufacturers typically engineer components and require suppliers to use the buyer's part numbers. The same has been true for Department of Defense suppliers, who are required to use the National Stock Number. However, for common materials that is sold to many different customers, this practice results in higher costs due to unique labeling for each customer and complex systems to maintain cross-references to each customer's numbers. These costs must be passed on to the customer. As the result of growing recognition of the costs and complexity, the construction industries should consider acceptance of CCPCS for the common suppliers. Therefore, the Industry Standard Coding scheme should be standardized to maximize the benefits of bar coding. Besides the Auto ID (e.g. bar coding), standard numbering also is integral to an EDI concept. To be most effective, EDI requires the sender and receiver of EDI transactions to use the same standard product numbers. Unique customer numbers for common materials in the construction also make implementation of EDI difficult. Benefits of EDI include accuracy, cycle time reduction, and elimination of clerical costs involved in transcribing documents and key entering product catalogs, purchase orders, invoices, and other transactions into computer systems.

\section{CONCLUSION}

1. The primary technological barrier in effectively adopting Auto ID technologies in the construction industry is the lack of CCPCS for encoding and transferring information.

2. The complex nature of construction and the vast number of items which go into construction creates severe difficulties in developing an all-encompassing information identification system.

3. Construction Information can be classified as primary or secondary and so forth. It is only mandatory that external information could be industry standardized although standardization of other information could encourage the development of a supporting software industry which could increase accuracy and reduce costs.
4. Some industries in the construction supply chain, such as the piping industry, are developing coding schemes. However, unless these efforts are integrated into an industry-wide CCPCS there will still be difficulties in introducing Auto ID procedures for on-site construction management.

5. Due to large investments made in developing common commodity system in other industries, construction could realize significant time and cost savings by utilizing the experience gained in the related areas.

6. Although the paper used bar code technology to prove the CCPCS's applicability and feasibility in construction, CCPCS also can be used in the other newly developed Auto ID technologies' construction application, like RFID.

\section{REFERENCES}

1. Allays, D. C., "UCC product identification standards," Scan Tech, Automatic Identification Manufacturers (AIM), pp. 1-4 (1992).

2. Chin, S., Yoon, S., Choi, C., and Cho, C., "RFID + 4D CAD for progress management of structural steel works in high-rise buildings," Journal of Computing in Civil Engineering, Vol. 22, No. 2, pp. $74-89$ (2008).

3. Ergen, E., East, B., and Kirby, J., "Tracking components and maintenance history within a facility utilizing radio frequency identification technology," Journal of Computing in Civil Engineering, Vol. 21, No. 1, pp. 11-20 (2007).

4. Forger, G. J., “Auto. ID \& EDI: Hotline to productivity,” Modern Material Handling, February, pp. 56-58 (1990).

5. Ghanem, G. and AbdelRazig, Y. A., "A framework for real-time construction project progress tracking," Earth \& Space 2006: Engineering, Construction, and Operations in Challenging Environment, pp. 1-8 (2006).

6. Jaselskis, E. J. and Misalami, T. E., "Implementing radio frequency identification in the construction process," Journal of Construction Engineering and Management, Vol. 129, No. 6, pp. 680-688 (2003).

7. Lansford, C. B. and Stukhart, G., "Costs and benefits of materials management systems," Journal of Construction Engineering and Management, ASCE, Vol. No. Nov., pp. 211-220 (1987).

8. Lisse, S. D., "Japanese industrial standards for the construction industry," ASTM Standardization News, February, New York, pp. 57-63 (1993).

9. Marilyn, S. S., "Industry standards and uses of Auto ID," Scan-Tech 89 Proceedings, AIM, pp. 15-17(1989).

10. Pan, N. H., Automatic Data Processing Technologies and Industry-Wide Information Transfer Standard in Construction, Ph.D. Dissertation of Civil Engineering, SUNY at Buffalo (1996).

11. Song, J., Haas, C. T., and Caldas, C. H., "Tracking the location of materials on construction job sites," Journal of Construction Engineering and Management, Vol. 132, No. 9, pp. 911-918 (2006).

12. The Construction Industry Institute (CII), Project Materials Management Handbook, A Report By The Construction Industry Institute Materials Management Task Force (1987). 